\title{
A status report on RNAi therapeutics
}

\author{
Akshay K Vaishnaw*, Jared Gollob, Christina Gamba-Vitalo, Renta Hutabarat, Dinah Sah, Rachel Meyers, Tony de \\ Fougerolles and John Maraganore
}

\begin{abstract}
Fire and Mello initiated the current explosion of interest in RNA interference (RNAi) biology with their seminal work in Caenorhabditis elegans. These observations were closely followed by the demonstration of RNAi in Drosophila melanogaster. However, the full potential of these new discoveries only became clear when Tuschl and colleagues showed that 21-22 bp RNA duplexes with 3" overhangs, termed small interfering (si)RNAs, could reliably execute RNAi in a range of mammalian cells. Soon afterwards, it became clear that many different human cell types had endogenous machinery, the RNA-induced silencing complex (RISC), which could be harnessed to silence any gene in the genome. Beyond the availability of a novel way to dissect biology, an important target validation tool was now available. More importantly, two key properties of the RNAi pathway - sequence-mediated specificity and potency - suggested that RNAi might be the most important pharmacological advance since the advent of protein therapeutics. The implications were profound. One could now envisage selecting disease-associated targets at will and expect to suppress proteins that had remained intractable to inhibition by conventional methods, such as small molecules. This review attempts to summarize the current understanding on siRNA lead discovery, the delivery of RNAi therapeutics, typical in vivo pharmacological profiles, preclinical safety evaluation and an overview of the 14 programs that have already entered clinical practice.
\end{abstract}

\section{Introduction}

Since the original reports of RNA interference (RNAi) in cells from a range of species [1-3], there has been increasing interest in harnessing this endogenous mechanism, which enables degradation of a specific mRNA, as a novel pharmacological approach to human disease. Indeed, from a drug discovery perspective, small interfering (si)RNAs have some distinct advantages over conventional drug therapies such as small molecules or antibodies (Table 1). However several major obstacles have had to be overcome before the entry of RNAi therapeutics to clinical trials. These include steps required for lead selection, the use of chemical modifications to confer appropriate biopharmaceutic properties, the design of formulations that enable delivery to a target tissue, and screening of these products for safety, including assessments for potential off-target effects. These aspects are addressed below and followed by a critical analysis of the 14 programs that have entered clinical development in the past decade. This review does not cover the related and rapidly expanding field of RNA therapeutics, which

\footnotetext{
* Correspondence: avaishnaw@alnylam.com

1 Alnylam Pharmaceuticals Inc., 300 Third Street, Cambridge, MA 02142, USA Full list of author information is available at the end of the article
}

addresses microRNAs (miRNAs) rather than messenger mRNAs, as targets.

\section{Lead discovery algorithms}

We and others have developed high-throughput algorithms to support screening and selection of a lead siRNA. De Fougerolles et al. [4] reviewed the various steps involved, which include a bioinformatic screen to identify duplexes 19-23 bp in length with minimal off-target complementarity, small-scale synthesis of a panel of siRNAs, in vitro assays for potency and nonspecific cytotoxicity, and assessment of in vivo pharmacology. Embedded in this primary screen are subscreens for stability in a biological matrix (for example, serum, cerebrospinal or bronchoalveolar lavage fluid) relevant to the target tissue, and additional screens for specificity (addressed below). The ubiquitous nature of RNases requires that in most cases, a lead siRNA needs to be stabilized. Increased stability can be achieved by chemically modifying the primary sequence. To date, the modifications used have been phosphodiester to phosphorothioate modifications on the backbone and 2"-O-methyl or other 2" substitutions on the ribose moieties [5]. This strategy has been influenced by the antisense oligonucleotide (ASO) field, 
Table 1: A comparison of various drug discovery attributes of siRNAs and small molecules

\begin{tabular}{lll}
\hline & siRNA & Small molecule \\
\hline Specificity & High, sequence driven & Low-medium, conformation driven \\
\hline Potency & Typically pM & Variable \\
\hline Number of accessible targets & $>>1000$ & 500 to 1,000 \\
\hline Number of potential leads and backups & $>>10$ to 100, depending on length of target & $<2$ to 3 \\
\hline Speed to lead molecule & & 2 to 4 years \\
\hline Species crossreactivity & 4 to 8 weeks & Low \\
\hline Manufacturing & High & Variable, can be complex
\end{tabular}

in which both modifications have been used extensively and which provides an accompanying body of safety data in preclinical species and in humans. Many additional modifications have been explored both for siRNAs and ASOs [5], including locked nucleic acids, in which the 4" carbon on the sugars is tethered to the 2" substituent, although fewer molecules of this type have to date reached clinical trials. For any given sequence, the number and position of the chemical modifications necessary is variable and requires an empiric approach. Given that chemical modifications, especially to the antisense or 'guide' strand of the duplex, can influence potency, each round of modifications also requires a secondary screen to determine maintenance of activity. However, at the end of this type of screening process, lead siRNAs with IC50 values in the low single-digit picomolar to femtomolar range can often be identified (Figure 1). The combination of attractive mechanism of action, efficiency of siRNA lead discovery and relative ease of siRNA manufacture explain why both biotechnology and pharmaceutical companies have shown great enthusiasm for RNAi therapeutics [6].

\section{Delivering RNAi therapeutics}

The $\sim 14 \mathrm{kDa}$ mass and polyanionic charge of a typical 21 bp siRNA duplex ensure that achieving good tissue bioavailability is often a greater challenge than lead selection. Despite this, both local and systemic delivery to various tissue and cellular compartments have been demonstrated preclinically $[4,7,8]$. For local delivery, administration of unmodified siRNA in simple formulations such as saline has resulted in target mRNA knockdown in a wide variety of tissues, including the respiratory and urogenital epithelia, central nervous system and the eye. Most of the local delivery studies have been in mice, and involve sub- stantial doses, presumably associated with high local concentrations that drive cellular uptake. Although the exact mechanism of uptake in most of these cases remains unknown, some notable effects have been observed, including decreasing respiratory syncitial virus (RSV) or parainfluenza virus (PIV) infection in respiratory epithelium $[9,10]$, herpes simplex virus-2 infection in the vaginal epithelium [11], 2',3'-cyclic nucleotide 3'phosphodiesterase expression in oligodendrocytes [12], huntingtin expression in neurons [13], and vascular endothelial growth factor (VEGF)-A [14] and VEGF receptor (VEGFR)I [15] expression in ocular tissues.

Systemic delivery of RNAi therapeutics offers both the greatest opportunities and challenges. An unmodified saline-formulated siRNA injected intravenously is subject to simultaneous RNase-mediated degradation and rapid renal excretion. Hence, any attempts at systemic delivery must involve mechanisms for increasing the circulation half-life $\left(t_{1 / 2}\right)$ of the siRNA, its distribution to an appropriate tissue compartment and then its uptake, followed by intracytoplasmic release and activity. In this regard, the greatest success to date has been achieved with respect to hepatic delivery, with three distinct approaches, each involving a conjugated or formulated siRNA, warranting review.

Soutschek et al. [16] were the first to report a delivery strategy with significant translational potential. In a mouse system, they demonstrated that cholesterol conjugation to the sense or 'passenger' strand of an ApoB-specific siRNA administered intravenously resulted in a significant reduction in clearance and an associated 16fold increase in $t_{1 / 2}$, relative to the unconjugated control (Figure 2). Subsequent work elucidated that the change in pharmacokinetic (PK) characteristics was secondary to loading of the conjugated siRNA into circulating lipopro- 


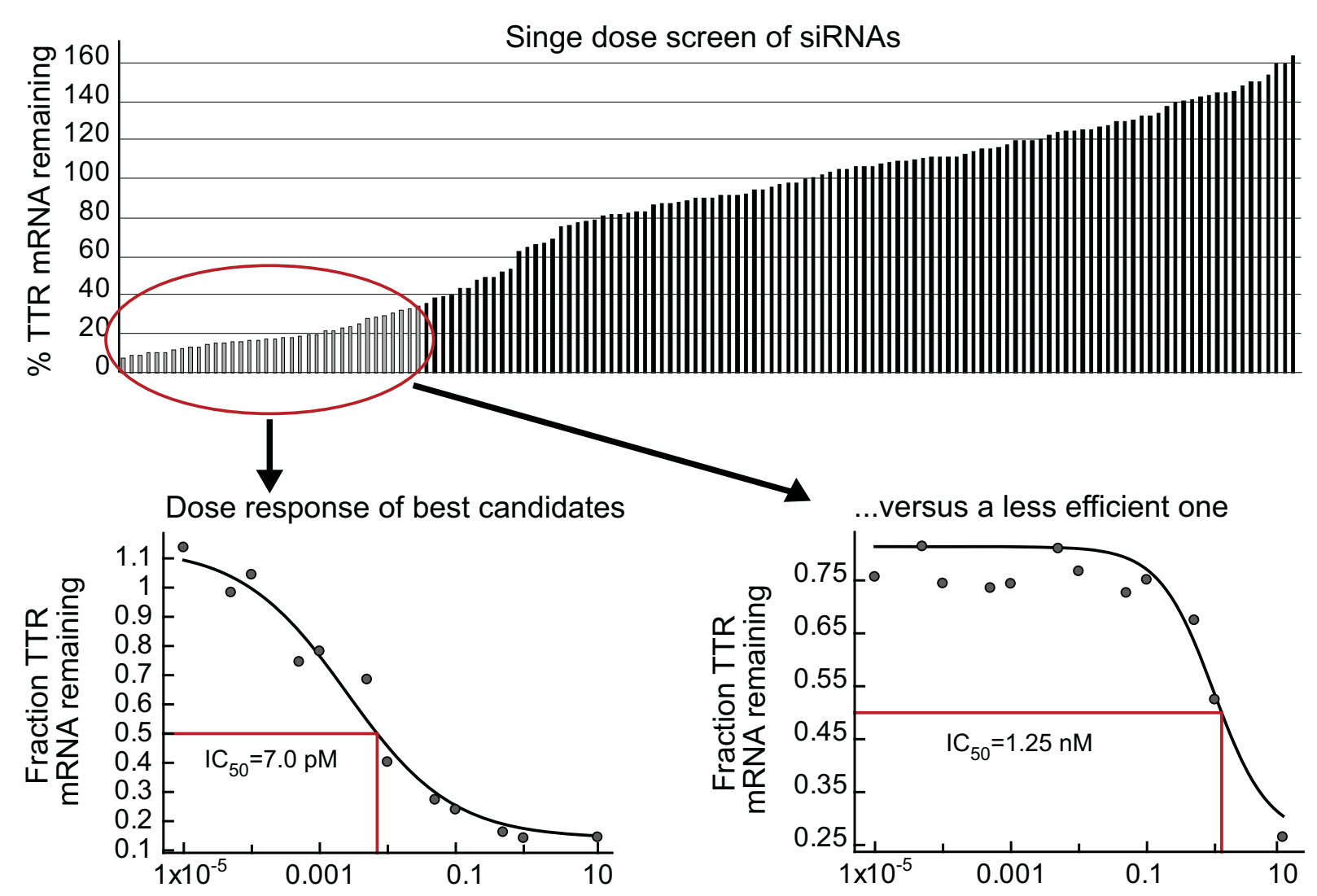

Figure 1 Small interfering (si)RNA Lead selection. A large panel of siRNAs identified by a bioinformatic screen were synthesized and tested in vitro for activity against the transthyretin transcript as measured by quantitative PCR. The upper part of the panel shows the entire panel tested in parallel at a given nanomolar siRNA concentration, and data are shown in rank order of potency, with each vertical line representing an individual siRNA. The bottom panel illustrates in vitro dose response curves for a potent versus a less potent molecule.

tein particles via the appended cholesterol moiety [17]. This also facilitated receptor-mediated uptake of the siRNA into hepatocytes, and resulted in $\sim 60 \%$ knockdown of ApoB mRNA in the mouse liver [16]. Notably, intravenous administration of cholesterol-conjugated siRNAs targeting ApoB also resulted in efficient knockdown of ApoB mRNA in the jejunum. More recently, conjugation-based approaches with other ligands have been used, such as prostate-specific membrane antigen aptamer-siRNA conjugates to deliver drug to tumor cells in vivo [18].

Two groups have reported liposomal nanoparticle (LNP)-mediated delivery of siRNA to the liver, demonstrating knockdown in the mouse [19] and the nonhuman primate [20]. In both studies, the LNP formulation, also known as a 'stable nucleic acid lipid particle' (SNALP), was composed of several non-covalently associated components (an ionizable lipid, polyethylene glycol (PEG)-lipid for prolonging $t_{1 / 2}$, cholesterol, and a neutral lipid) which self-assembled and encapsulated the siRNA. Morrissey et al. [19] were able to show that rela- tive to unencapsulated siRNA, LNPs that encapsulated a variety of anti-hepatitis B virus (HBV) siRNAs showed reduced plasma clearance and efficient hepatic uptake with dose-dependent, potent $\left(>1 \log _{10}\right)$ and durable knockdown of circulating HBV DNA levels in a mouse model of infection. Zimmermann et al. [20] also demonstrated hepatic uptake of LNPs with specific knockdown of $\mathrm{ApoB}$ in the non-human primate. The pharmacodynamic (PD) profile in this study was notable not only for the extent of hepatic ApoB mRNA knockdown (>80\%), but also for its translation to systemic lowering of lowdensity lipoprotein cholesterol (LDLc) (by 82\%) which persisted for several weeks after a single dose. The latter observation was particularly interesting because the drug was undetectable in the liver of animals beyond $48 \mathrm{hrs}$, suggesting an apparent PK-PD hysteresis. Recent work with more sensitive quantitative PCR assays has clarified that in fact the drug is present (and presumably stabilized in RISC) at all time points when PD is observed after LNP-mediated siRNA delivery [21] (Alnylam Pharmaceuticals Inc., unpublished observations, Renta Hutabarat). 


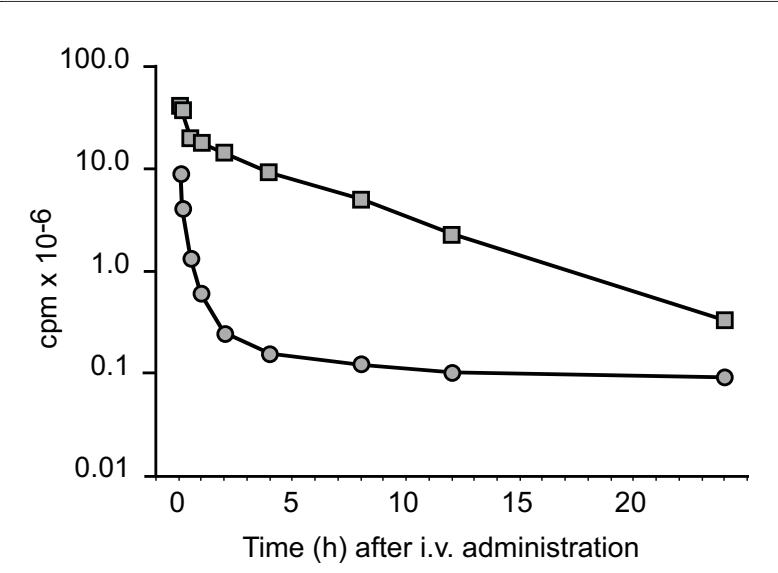

Figure $\mathbf{2}$ In vivo pharmacokinetic profile of a cholesterol-conjugated (squares) and unconjugated (circles) radio-labeled small interfering (si)RNA against ApoB in the mouse [16]. The half-life and clearance were calculated to be 95 minutes and $0.5 \mathrm{~mL} /$ minute and 6 minutes and $17.6 \mathrm{~mL} /$ minute, for the conjugated and unconjugated molecules, respectively.

The mechanism of ionizable LNP-mediated delivery has been dissected, and in vivo it involves the opsonization of the LNP by ApoE in the circulation, LDL receptor-mediated uptake of the opsonized particles by hepatocytes, and then endosomal release of siRNA into the cytoplasm (Alnylam Pharmaceuticals Inc.) [22].

The third systemic delivery approach of note involves multicomponent complexes. Rozema et al. [23] studied particles composed of siRNA conjugated with a dynamic polyconjugate and complexed with PEG to extend $t_{1 / 2}$, plus a liver targeting ligand, $\mathrm{N}$-acetyl galactosamine (NAG). This strategy was successfully used in rodents and non-human primates to show potent and durable hepatic ApoB knockdown with associated reduction in circulating LDLc. Mechanistically, the role of NAG was crucial, as its replacement with mannose abrogated uptake by hepatocytes and instead directed delivery to other hepatic cellular compartments such as Kupffer cells. Bartlett et al. [24] used a similar multicomponent concept but complexed a ribonucleotide reductase (RRM2) siRNA to cationic cyclodextrin, along with PEG and a targeting ligand, transferrin. In this system, the transferrin allowed delivery to extrahepatic sites, and target mRNA knockdown was achieved in a subcutaneous tumor xenograft.

Of the three hepatic delivery concepts above, the LNPmediated approach has received the most attention. Recently, optimization of LNP structure and function has resulted in potent in vivo knockdown at doses as low as $0.01 \mathrm{mg} / \mathrm{kg}$ [25] (whereas in local delivery (see above) doses are typically $>1 \mathrm{mg} / \mathrm{kg}$ ). LNP-mediated delivery of RNAi therapeutics has now been applied to several different target mRNAs other than ApoB and has been described in five species including the mouse, rat, hamster, guinea pig and non-human primate [20,25-28] (Alnylam Pharmaceuticals Inc., unpublished observations). In terms of pharmacology, the LNP experiments have fully validated the drug-like behavior of siRNAs. For all the LNP studies cited, there is a consistency of observations with respect to PD onset, which generally occurs within $24 \mathrm{hrs}$ with peak effects at 48-72 hrs; duration, which lasts several weeks depending on the potency (and perhaps stability) of the siRNA concerned; strict dose dependency; and return of PD to baseline. Akinc et al. [27] also elegantly showed reproducibility of effects with multiple treatment cycles by giving a LNP-formulated Factor VII siRNA once monthly. Many studies have also confirmed the RNAi mechanism of action in vivo by demonstrating (via 5" rapid amplification of cDNA ends assay) the anticipated cleavage site in the target mRNA and the lack of effect by identical LNP-mediated delivery of an irrelevant siRNA [20,26-28]. Overall, the potency, predictable and reproducible pharmacology across different targets and species (as anticipated for an endogenous mechanism), the selectivity and the clear mechanism of action suggest a robust translational potential for LNPbased hepatic delivery of RNAi therapeutics.

To fully exploit the therapeutic potential of RNAi, systemic delivery beyond the liver will need to be accomplished, and indeed some creative approaches have been reported. With optimization to further increase the circulation $t_{1 / 2}$ relative to LNPs delivering to the liver, LNPmediated extrahepatic delivery to subcutaneous tumors in mice has been achieved [29]. Antibodies facilitating siRNA delivery offer several advantages, including an intrinsic targeting mechanism and good PK properties. Antibody-protamine fusion proteins have been shown to complex with siRNAs and reported to deliver specifically to subcutaneous tissue [30] and to lung [31] tumors in mice. By bringing together the advantages of LNPs and antibodies, Peer et al. [32] devised sophisticated neutral LNPs with a covalently attached antibody against $\beta 7$ integrin and carrying an anticyclin D1 siRNA complexed with protamine. Using this approach, they were able to show specific knockdown of cyclin D1 in gut mononuclear leucocytes with translation to therapeutic effects in a mouse model of colitis. Oral delivery of RNAi therapeutics would offer the greatest convenience if translatable clinically. Recently, glucan-encapsulated siRNA particles were reported to be efficient oral delivery vehicles to target gut macrophages [33]. Although the extrahepatic delivery concepts above demonstrate progress, further work is required to reproduce the observations and demonstrate a clear RNAi-dependent mechanism of action, much as described for extrahepatic delivery to subcutaneous tumors [29]. 


\section{Safety screening: in vitro}

Several in vitro studies over the past decade have suggested that RNAi therapeutics have the potential for offtarget effects [34]. These are potentially of three types: sequence-dependent/RISC-mediated [35-37], sequenceindependent/RISC-mediated [38,39] and sequence-independent/innate immune-mediated [40-42]. The first, produced by binding of the sense or antisense strand to bystander mRNA(s), might lead to an RNAi-mediated off-target effect, or if hybridization occurs in the $3^{\prime}$ untranslated region (UTR) then potentially to miRNAlike translational suppression. Bioinformatics, of course, plays a crucial role in minimizing these potential liabilities by deprioritizing sequences that have significant offtarget complementarity. Rarely, sequences of interest that have high off-target potential cannot be avoided. In those instances the relative on-target versus off-target halfmaximal inhibitory concentrations (IC50s) should be determined in vitro (much as for small molecules). We have found that this approach generally reveals that, despite high degrees of off-target complementarity, in vitro potency is clearly distinguishable with IC50s for onand off-target effects separated by several log orders (Figure 3).

Notwithstanding the utility of a robust bioinformatic screening algorithm, multiple studies have detected widespread transcript dysregulation [34]. Most of the studies have relied on in vitro siRNA transfection followed by transcriptome readouts. These types of datasets require cautious interpretation for several reasons, including the lack of clear cause and effect relationships (that is, how much of the transcriptional dysregulation is secondary to on-target versus off-target knockdown), the relatively modest degree of transcript dysregulation described (typically an increase or decrease of $\leq$ two-fold) and the lack of protein or functional readout. When protein correlates have been examined, the siRNA-associated off-target effects have resulted in either very subtle effects or in a lack of quantitative relationship between change in bystander mRNA and protein expression [43]. Finally, studies examining off-target effects have used molecules with suboptimal potency and specificity requiring suprapharmacologic doses to achieve target knockdown. For example, Bilanges and Stokoe [44] observed significant off-target effects with ASO- and siRNA-based approaches against a specific target, phosphoinositidedependent kinase (PDK)1; however, they used high, potentially cytotoxic concentrations (>300 nM, in contrast to the pharmacologic (picomole to femtomole) levels discussed above (Figure 1).

From a drug development viewpoint, it is widely acknowledged that many molecules, including ASOs [45] and small molecules, from acetaminophen [46] to kinase inhibitors [47], all show diverse effects on transcriptional profiling analyses. Nevertheless, preclinical transcriptional profiling has not been routinely used in lead selection, as these effects have not been shown to have any in vivo consequence in terms of safety or efficacy.

Sequence-independent off-target effects refer to either saturation of the endogenous RISC machinery [38,39] or to the immunostimulatory potential of siRNAs [48]. Single-stranded and double-stranded RNAs, particularly chemically unmodified sequences, can stimulate the innate immune system via Toll-like receptor (TLR)-3 [14], TLR-7/8 [40-42] and non-TLR pathways, such as retinoic acid inducible gene (RIG)-I [49] or PKR [50]. Cytokine induction can contribute to target suppression via an RNAi-independent mechanism [14,51]. Eliminating this proinflammatory liability is therefore crucial from both a safety and efficacy perspective. Tractable in vitro $[10,40]$ and in vivo $[41,52]$ preclinical assays exist, which can assess the proinflammatory potential of an siRNA. Similar approaches were validated when proinflammatory DNA oligonucleotides acting as TLR-9 agonists were studied preclinically and then in clinical practice $[53,54]$. From a practical viewpoint, because there is no a priori knowledge as to which pathway might be engaged for any candidate siRNA, a wide range of inflammatory markers should be evaluated during lead selection, including type I and II interferons, and cytokines and chemokines induced by TLR-3, TLR-7 and TLR8 agonists. The use of appropriate control siRNAs is crucial in immunostimulatory screening assays, and a widely used, chemically modified green fluorescent protein (GFP) sequence has served as an important negative control for many groups [51]. In certain cases, a given sequence with proinflammatory potential might be very desirable for potency or other considerations. Fortunately, both increased stability and reduced pro-inflammatory liabilities can be achieved simultaneously by chemical modifications (Figure 4). Again, the process of modification is empiric and requires subsequent confirmation that potency has been maintained. It is to be hoped that greater knowledge of TLR recognition will enhance bioinformatic exclusion of proinflammatory sequences and guide chemical modification strategies to specific motifs $[40,41,55]$, increasing overall screening efficiency and throughput.

\section{Safety screening: in vivo}

The entry of an RNAi therapeutic program into clinical practice requires completion of good laboratory practice (GLP)-compliant preclinical toxicological studies. Studies in the rat and dog are used preclinically for the vast majority of drugs destined for clinical practice. By contrast, ASO programs set a precedent by using mouse and non-human primate [56]. It is our understanding that all RNAi therapeutics currently in clinical trials used a 


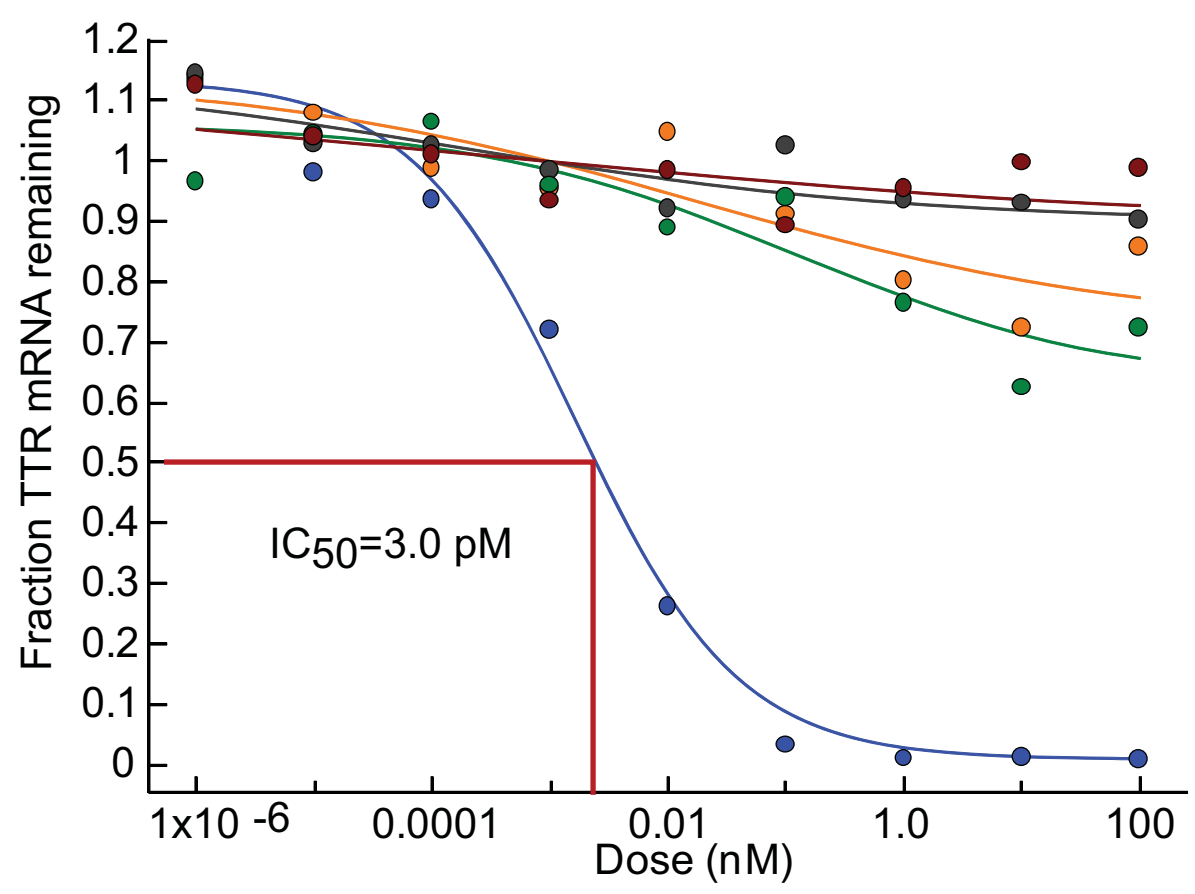

Figure 3 Comparison of on- and off-target effects. A putative lead molecule was tested in vitro to evaluate potency against the intended target, transthyretin and four sequence-related off targets defined by the bioinformatic screen. The percentage reduction in transythyretin levels was measured by quantitative PCR.

rodent and non-human primate as preclinical toxicological species. The reasons underlying this choice are the same for ASO and RNAi programs, and include the availability of bioinformatic databases to enable design of a single crossreactive siRNA for use in rodent, non-human primates and humans; the ability to leverage prior animal pharmacology work with the relevant siRNA; the availability of tools and assays such as immunological readouts and knockout mice; and finally the hope that the non-human primate represents the closest physiology to that of humans.

Some principles regarding the design of preclinical toxicology studies for RNAi programs are now discussed. In both test species, low, medium and high exposures should be achieved using the low dose at or near the anticipated pharmacological dose and the highest dose to represent a significant excess, allowing definition of a maximum tolerated dose. Dosing schedule and timing of terminal sacrifice should take into account the duration of pharmacologic effect, given that single intravenous doses can exert target mRNA knockdown for several weeks, as discussed above. If the candidate siRNA is not fully complementary to the target mRNA in both preclinical species, then a sequence should be selected that is crossreactive to at least one preclinical species, allowing study of on-target toxicity secondary to target mRNA knockdown. For systemic delivery programs, adequate controls should be considered including, where appropriate, comparison of formulated candidate siRNA, formulated irrelevant siRNA and naked (unformulated) siRNA, in order to dissect the relative contributions of siRNA and formulation to the toxicological profile. Beyond the safety endpoints that would be expected in a GLP toxicological program, additional readouts of interest include cytokines and chemokines, specifically those relating to immunostimulation-related effects via TLR activation (see above). Currently, it is not known which preclinical species is most predictive of immunostimulation-mediated effects but a combination of in vitro screening along with in vivo readouts in two species before clinical trials are held is an appropriately conservative approach. Finally, suitable high-sensitivity bioanalytical assays need to be incorporated to track the siRNA [57], formulation components (if they contribute to the overall profile) and associated metabolites.

Details of GLP toxicology programs are rarely published, and few data are in the public domain. However, no evidence to suggest toxicities similar to those seen with first-generation ASO [56] has emerged. Accordingly, there are no reports of siRNA-related complement activation, coagulation defects, immunostimulation and lymphoid hyperplasia or renal tubular changes. We and 

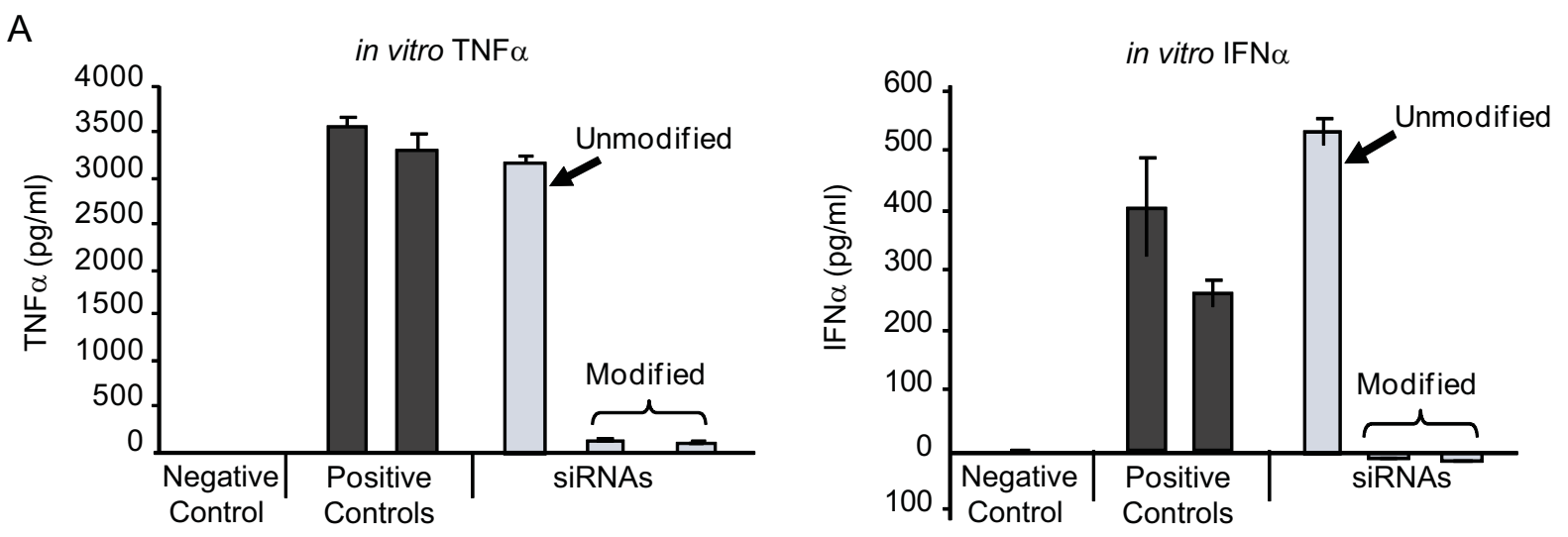

B

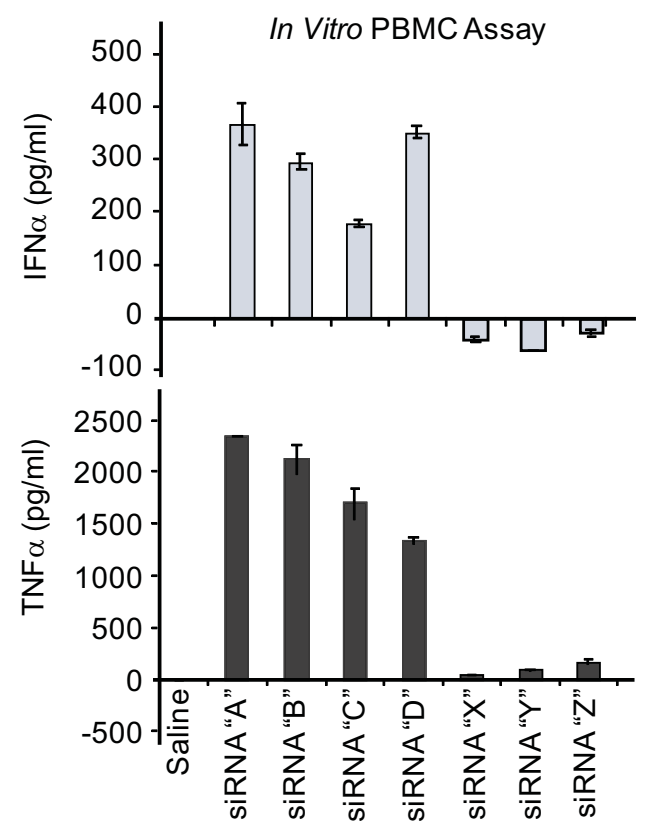

In Vivo Serum Cytokines i.v. bolus $4 \mathrm{mg} / \mathrm{kg}$ siRNA in LNP01

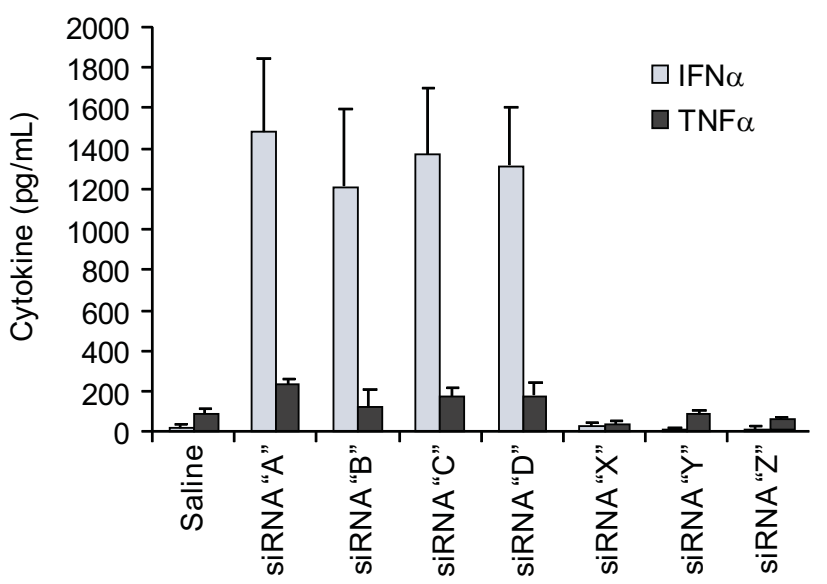

Figure 4 Profiling immunostimulatory small interfering (si)RNAs. (a) A panel of siRNAs including negative and positive controls were evaluated in an in vitro human peripheral blood mononuclear cell (PBMC) assay as described previously [10] with supernatants examined for tumor necrosis factor (TNF) (left panel) and interferon-a (right panel) levels. The right-hand side of each panel has a chemically unmodified siRNA, which is compared with the same sequence after incorporation of a combination of phosphorothioate and 2'-O-methyl chemical modifications. (b) The left-hand panels show a series of immunostimulatory (A-D) and non- immunostimulatory (X-Z) siRNAs evaluated in an in vitro PBMC assay. The right-hand panel shows plasma cytokine profiles in mice injected intravenously with the same siRNAs formulated in LNP01 [26]. Common immunostimulatory siRNAs are identified by the in vitro and in vivo assays.

others have studied unformulated siRNAs at doses $>100$ $\mathrm{mg} / \mathrm{kg}$ in the rodent and non-human primate and found them to be well tolerated, although this is in all likelihood secondary to the rapid renal elimination of naked (unformulated) siRNAs. For systemic delivery formulations such as LNPs and multicomponent complexes with approximate diameters of $50-110-15 \mathrm{~nm}$, respectively, particle size might be an important determinant of biodistribution and therefore target organs for toxicity. For these types of nanoparticles, vascular egress would be expected predominantly in tissues with fenestrated $(\sim 100$ $\mathrm{nm}$ apertures) microvasculature, such as liver, spleen and bone marrow. Consistent with this and the substantial blood flow through the liver, hepatic transaminase elevations were reported in association with LNPs [20] and multicomponent complexes [24]. Abrams et al. [21] studied LNP201, a cationic LNP encapsulating an anti-SSB siRNA. They demonstrated that LNP201 localized predominantly to liver and spleen, and with the use of appropriate controls found that the formulation (and not the 
siRNA) had proinflammatory properties and at high doses was associated with hepatotoxicity. The latter could be abrogated by corticosteroid pretreatment. Thus, the liver might come to be recognized as an important target organ of toxicity as we learn more about systemic delivery formulations.

\section{Clinical RNAi pipeline}

A total of 14 RNAi therapeutic programs have entered clinical practice in the past decade (Table 2). Currently few publications detailing these clinical experiences have emerged, thus much of the information that follows has had to be gleaned from corporate press releases or the US National Institutes of Health hosted database of ongoing and completed clinical trials http://www.clinicaltrials.gov. Of the 14 programs, seven involve local/topical delivery to the eye (four), respiratory tract (two) and skin (one). The remaining seven are systemic programs targeting liver (two), hepatic and extrahepatic cancer (three), leukocytes (one) and kidney (one). All 14 programs are being developed for indications with a high degree of unmet medical need. A review of previous oligonucleotide programs reveals that the ASO field was hampered until recently by a lack of clear proof of concept in humans, largely because of two factors: poor target validation and lack of clear PD readouts in early clinical development [58]. There is significant variability in the degree of prior target validation across the global RNAi pipeline. Six of the 14 programs (ALN-RSV, ALN-VSP, ALN-TTR, TD101, bevasiranib, Bcr-abl) have clear target validation, and the other eight programs address targets of significant interest (for example, p53 for kidney injury or RTP801 for age-related macular degeneration (AMD)), but lack robust prior validation. Equally, only a few programs (ALN-TTR, ApoB-SNALP) offer the possibility of early PD demonstration of target knockdown, whereas the rest will require further development into phase II before adequate proof of concept is achieved. ALN-RSV has achieved initial proof of concept, and is discussed separately below.

Table 2 shows how RNAi therapeutic programs demonstrate some of the unique advantages of the platform. Several have targets (RSV $(\mathrm{N})$ nucleocapsid protein, p53, TTR, ApoB, K6a) that would be 'undruggable' by small molecules or protein moieties. The attempt to target Bcrabl and mutant K6a shows the potential for allele-specific knockdown. Finally, ALN-VSP builds on data from animal models in which five transcripts were suppressed in parallel [28] by simultaneously targeting two transcripts, VEGF and kinesin spindle protein (KSP), a clear advantage in complex indications such as cancer.

From an overall safety perspective, almost 1500 patients and healthy volunteers will soon have been enrolled onto RNAi clinical programs. In total, 1065 have already been studied across all phases of clinical development, including 522 in the bevasiranib phase III studies. These numbers are important because a unique siRNArelated adverse event occurring at a high incidence (for example $>10 \%$ ), would probably already have been identified. Equally, no data have emerged to suggest serious adverse events linked to siRNA exposure, and none of the programs have been placed on 'clinical hold' by regulatory agencies, a probable outcome if untoward safety events were being uncovered. The largest fraction of the safety experience (1284 subjects) relates to the three ocular programs (bevasiranib, PF-04523655 and AGN211745) and to the respiratory program (ALNRSV), which suggests good local tolerability to RNAi therapeutics.

ALN-RSV (Alnylam Pharmaceuticals Inc., Cambridge, MA, USA) in phase $2 \mathrm{~b}$ is currently the most advanced program in the global RNAi pipeline. It uses an unmodified siRNA formulated in saline targeting the RSV N gene transcript. Three phase I studies (two intranasal [59] and one inhalational [60]) showed safety and tolerability at doses up to $3 \mathrm{mg} / \mathrm{kg}$. In 2008, this program reported the first initial human proof of concept for an RNAi program. In a double-blind, randomized, placebo-controlled study $(n=88)$ of safety and efficacy, prophylactic intranasal treatment with ALN-RSV was shown to decrease the incidence of experimental upper respiratory tract infection with RSV [60]. Since then, another double-blind, randomized, placebo-controlled phase II study $(n=24)$ has been completed with inhaled ALN-RSV in lung transplant recipients naturally infected with RSV. The findings demonstrated improved symptom scores and lung function in favor of ALN-RSV, and the program will shortly start a phase IIb study in the same indication [60]. The ALN-RSV program also illustrates the stability and compatibility of RNAi therapeutics with devices, because the inhalational delivery requires a nebulizer, and extensive evaluation has demonstrated structural and functional integrity of the drug before and after nebulization.

The drug PF-04523655 (Pfizer, NYC, NY, USA)is administered via the intra-ocular route and targets RTP801, a pro-angiogenic factor. It is currently in phase II development for wet AMD [61] and diabetic macular edema [62]; no further details are yet available. QPI-1002 (Quark Pharmaceuticals Inc., Fremont, CA, USA) is a systemically administered siRNA targeting p53, which is also in phase II development $[63,64]$. Two studies evaluating the safety of QPI-1002 in different patient populations have been completed [65]. These include a phase I study for the prevention of acute kidney injury in patients undergoing major cardiovascular surgery, and the first part of a phase I/II study in renal transplant recipients for the prevention of delayed graft function. Both PF04523655 and QPI-1002 are thought to be in simple for- 
Table 2: The global RNA interference pipeline*

\begin{tabular}{|c|c|c|c|c|c|}
\hline Sponsor & Program (clinical stage) & Status & Target & Indication & Number enrolled \\
\hline $\begin{array}{l}\text { Alnylam/Cubist/Kyowa } \\
\text { Kirin }\end{array}$ & ALN-RSV (phase Ilb) & Ongoing & RSV nucleocapsid & Adult RSV infection & 354 \\
\hline Pfizer/Quark & PF-04523655 (phase II) & Ongoing & RTP801 & $\begin{array}{l}\text { (1)AMD, diabetic } \\
\text { macular edema }\end{array}$ & $244 \dagger$ \\
\hline Quark & QPI 1002 (phase II) & Ongoing & p53 & $\begin{array}{l}\text { (1)Acute kidney injury, } \\
\text { delayed graft function }\end{array}$ & $56+$ \\
\hline Zabecor & Excellair (phase II) & Ongoing & Syk kinase & Asthma & $?$ \\
\hline Alnylam & ALN-VSP (phase I) & Ongoing & VEGF, KSP & $\begin{array}{l}\text { Primary and } \\
\text { secondary liver cancer }\end{array}$ & $55+$ \\
\hline Calando & CALAA-01 (phase I) & Ongoing & RRM2 & Cancer & $36+$ \\
\hline Silence & Atu-027 (phase I) & Ongoing & PKN3 & Cancer (Gl, lung other) & $33+$ \\
\hline Sylentis & SYL040012 (phase I) & Ongoing & $\begin{array}{l}\beta 2 \text { adrenergic } \\
\text { receptor }\end{array}$ & Glaucoma & $?$ \\
\hline Alnylam & ALN-TTR (phase I) & Ongoing & $T T R$ & TTR amyloidosis & $\begin{array}{l}\text { Enrollment begins } \\
\mathrm{H} 1,2010\end{array}$ \\
\hline Opko & Bevasiranib (phase III) & Terminated & VEGF-A & AMD & 522 \\
\hline Allergan/SIRNA & AGN211745 (phase II) & Terminated & VEGFRI & AMD & 164 \\
\hline Tekmira & ApoB SNALP (phase I) & Completed & ApoB & Hypercholesterolemia & 23 \\
\hline Transderm & $\begin{array}{l}\text { TD101 (phase I } \\
\text { completed) }\end{array}$ & Completed & Mutant K6a & $\begin{array}{l}\text { Pachyonychia } \\
\text { congenita }\end{array}$ & 1 \\
\hline Univ. Duisberg-Essen‡ & $\begin{array}{l}\text { Bcr-abl (phase I } \\
\text { completed) }\end{array}$ & Unknown & Bcr-abl oncogene & CML & 1 \\
\hline \multicolumn{6}{|c|}{$\begin{array}{l}\text { AMD = age-related macular degeneration; } \mathrm{CML}=\text { chronic myeloid leukemia; } \mathrm{Gl}=\text { gastrointestinal; } \mathrm{KSP}=\text { kinesin spindle protein; } \mathrm{PKN}=\text { protein } \\
\text { kinase } \mathrm{N3} ; \mathrm{RRM} 2=\text { ribonucleotide reductase } \mathrm{M} 2 ; \mathrm{RSV}=\text { respiratory syncytial virus; } \mathrm{RTP}=; \mathrm{TT} \mathrm{R}=\text { transthyretin; } \mathrm{VEGF}=\text { vascular endothelial growth } \\
\text { factor; } \mathrm{VEGFRI}=\text { vascular endothelial growth factor receptor I. } \\
\text { *All data from corporate websites, press releases and http://www.clinicaltrials.gov } \\
\text { †Enrollment ongoing } \\
\text { fFrom Koldehoff et al., } 2007\end{array}$} \\
\hline
\end{tabular}

mulations, but the exact details are not known. The three cancer programs, ALN-VSP (Alnylam Pharmaceuticals Inc.) [66], CALAA-01 (Calando Pharmaceuticals, Pasadena, CA, USA) [67] and Atu-027 (Silence Therapeutics, London, UK) [68] are all systemic delivery approaches that are in phase I studies. ALN-VSP and Atu-027 rely on LNP-mediated delivery $[60,69]$ whereas CALAA-01 deploys a multicomponent complex delivery system [25].
All three programs are at early stages and no data have yet been released, although preliminary ALN-VSP data are expected by mid 2010. No data are available for the asthma program, Excellair (targeting syk kinase), other than that in phase I, a total of 21 daily inhalational doses were well tolerated [70].

Most recently, Tekmira Pharmaceuticals' (Burnaby, BC, Canada) systemic delivery program Apo-B SNALP com- 
pleted its phase I study, providing some of the earliest systemic delivery results with an RNAi therapeutic. In total, 23 adult volunteers with mild hypercholesterolemia were enrolled, of whom 17 were exposed to Apo-B SNALP (Apo-B siRNA in an LNP formulation), the rest receiving placebo. Of three patients treated at the highest dose, $0.6 \mathrm{mg} / \mathrm{kg}$, one experienced flu-like symptoms attributed to the siRNA; no other laboratory abnormalities (including changes in liver function tests) or safety events were reported. Interestingly, two of the patients on this dose patients showed reductions in circulating LDLc of $16.3 \%$ to $21.1 \%$ [71].

As would be expected, several RNAi therapeutic programs have been terminated. Bevasiranib (Opko Health Inc., Miami, FL, USA) is delivered via the intravitreal route and targets VEGF. In 2006, a randomized, doubleblind, phase II study comparing three doses was completed patients with in wet AMD $(n=129)$ [72]. The safety data were encouraging, but the absence of a placebo arm prevented interpretation of any efficacy signals. Despite this limitation, and a report that its efficacy might be mediated via TLR-3 activation [14], 330 patients were enrolled in a phase III trial to study the safety and efficacy of bevasiranib in wet AMD [73]. Unfortunately, the study was terminated prematurely after the Independent Data Monitoring Committee reported that although safety was acceptable, the study was unlikely to reach its primary endpoint, an improvement in visual acuity [74]. Similarly, the intravitreal program AGN211745 (Allergan Inc., Irvine, CA, USA) which targets VEGFRI for wet AMD, was also terminated in phase II [75] after initial positive reports of efficacy from an earlier study [76]. AGN211745 too was shown to be possibly mediating its effects in preclinical models of AMD via TLR-3 activation [14].

From all the RNAi programs to date, only two, Bcr-abl and TD101 (Transderm Inc., Santa Cruz, CA, USA), are currently associated with completed safety and efficacy studies that have been published. However, both programs enrolled only one patient each. Koldehoff et al. [77] treated a single patient with recurrent CML by systemic administration of a formulated siRNA against Bcr-abl; however, the reported proof of concept with Bcr-abl knockdown in circulating leukemic cells is difficult to interpret because of the use of concomitant medications. Leachman et al. [78] reported a phase 1b study in a single patient with pachyonychia congenita, an autosomal dominant condition with painful palmoplantar calluses secondary to a keratin K6a mutation. The safety and efficacy of TD101 was tested in a 17-week, prospective, doubleblind, split-body, vehicle-controlled, dose-escalation trial on a single patient. Randomly assigned solutions of TD101 or vehicle control were injected into symmetric plantar calluses on the opposite feet. No adverse events occurred during the trial or in the 3-month washout period. Subjective patient assessment and physician clinical efficacy measures revealed regression of callus on the siRNA-treated, but not on the vehicle-treated foot.

\section{Conclusions}

With barely a decade since its initial characterization, the translation of RNAi biology toward RNAi therapeutics has progressed at a rapid pace. Moreover, the following years promise to be crucial for demonstration of the safety and efficacy of this new method in controlled, randomized studies. Certainly, much remains to be accomplished. In delivery research and preclinical studies, further advancement of the field will require continued progress in conjugation and formulation strategies. It would be naive to believe that any one single technology will provide all the solutions, so it is gratifying to see such a broad-based effort across multiple delivery technologies under investigation in academia and industry. In development efforts, many milestones remain to be achieved, including the conduct of large phase III studies and regulatory approvals. Of course, it is likely that there will be product failures, which could be accounted for by a number of factors including target selection, delivery technologies, clinical trial design and even commercial considerations. Nevertheless, the steadfast commitment in the field is apparent in the advancement of this critically needed innovation to patients.

\section{Competing interests}

All authors are employees of Alnylam Pharmaceuticals Inc., Cambridge, MA, USA which is engaged in the discovery and development of RNAi therapeutics.

\section{Authors' contributions}

The primary draft was generated by one of us (AKV) after many useful planning and guiding discussion with the other authors. All authors then contributed additional sections and helped with critical review and editing, leading to the final draft.

\section{Acknowledgements}

We are grateful to numerous Alnylam colleagues and collaborators who have helped in the development of the work described in this paper and for the many associated useful discussions. Special thanks to Maryellen Livingston for her expert technical help with the table and figures.

\section{Author Details}

Alnylam Pharmaceuticals Inc., 300 Third Street, Cambridge, MA 02142, USA

Received: 17 February 2010 Accepted: 8 July 2010

Published: 8 July 2010

\section{References}

1. Fire A, Xu S, Montgomery MK, Kostas SA, Driver SE, Mello CC: Potent and specific genetic interference by double-stranded RNA in Caenorhabditis elegans. Nature 1998, 391:806-11.

2. Kennerdell JR, Carthew RW: Use of dsRNA-mediated genetic interference to demonstrate that frizzled and frizzled 2 act in the wingless pathway. Cell 1998, 95:1017-26.

3. Elbashir SM, Harborth J, Lendeckel W, Yalcin A, Weber K, Tuschl T: Duplexes of 21-nucleotide RNAs mediate RNA interference in cultured mammalian cells. Nature 2001, 411:494-8. 
4. de Fougerolles A, Vornlocher HP, Maraganore J, Lieberman J: Interfering with disease: a progress report on siRNA-based therapeutics. Nat Rev Drug Discov 2007, 6:443-53.

5. Swayze EE, Bhat B: The medicinal chemistry of oligonucleotides. In Antisense Drug Technologies, Principles, Strategies and Applications 2nd edition. Edited by: Crooke ST. CRC Press: Taylor and Francis Group; 2008:143-82.

6. Haussecker D: The business of RNAi therapeutics. Hum Gene Ther 2008 19:451-62.

7. Novobrantseva TI, Akinc A, Borodovsky A, de Fougerolles A: Delivering silence: advancements in developing siRNA therapeutics. Curr Opin Drug Discov Devel 2008, 11:217-24.

8. Whitehead KA, Langer R, Anderson DG: Knocking down barriers: advances in siRNA delivery. Nat Rev Drug Discov 2009, 8:129-38.

9. Bitko V, Musiyenko A, Shulyayeva O, Barik S: Inhibition of respiratory viruses by nasally administered siRNA. Nat Med 2005, 11:50-5.

10. Alvarez R, Elbashir S, Borland T, Toudjarska I, Hadwiger P, John M, Roehl I, Morskaya SS, Martinello R, Kahn J, Van Ranst M, Tripp RA, DeVincenzo JP, Pandey R, Maier M, Nechev L, Manoharan M, Kotelianski V, Meyers R: RNA interference-mediated silencing of the respiratory syncytial virus nucleocapsid defines a potent antiviral strategy. Antimicrob Agents Chemother 2009, 53:3952-62.

11. Palliser D, Chowdhury D, Wang QY, Lee SJ, Bronson RT, Knipe DM, Lieberman J: An siRNA-based microbicide protects mice from lethal herpes simplex virus 2 infection. Nature 2006, 439:89-94.

12. Querbes W, Ge P, Zhang W, Fan Y, Costigan J, Charisse K, Maier M, Nechev L, Manoharan M, Kotelianski V, Sah DW: Direct CNS delivery of siRNA mediates robust silencing in oligodendrocytes. Oligonucleotides 2009, 19:23-30.

13. DiFiglia M, Sena-Esteves M, Chase K, Sapp E, Pfister E, Sass M, Yoder J, Reeves P, Pandey RK, Rajeev KG, Manoharan M, Sah DW, Zamore PD, Aronin N: Therapeutic silencing of mutant huntingtin with siRNA attenuates striatal and cortical neuropathology and behavioral deficits. Proc Natl Acad Sci USA 2007, 104:17204-9.

14. Kleinman ME, Yamada K, Takeda A, Chandrasekaran V, Nozaki M, Baffi JZ, Albuquerque RJ, Yamasaki S, Itaya M, Pan Y, Appukuttan B, Gibbs D, Yang Z, Karikó K, Ambati BK, Wilgus TA, DiPietro LA, Sakurai E, Zhang K, Smith JR, Taylor EW, Ambati J: Sequence- and target-independent angiogenesis suppression by siRNA via TLR3. Nature 2008, 452:591-7.

15. Shen J, Samul R, Silva RL, Akiyama H, Liu H, Saishin Y, Hackett SF, Zinnen S, Kossen K, Fosnaugh K, Vargeese C, Gomez A, Bouhana K, Aitchison R, Pavco P, Campochiaro PA: Suppression of ocular neovascularization with siRNA targeting VEGF receptor 1. Gene Ther 2006, 13:225-34.

16. Soutschek J, Akinc A, Bramlage B, Charisse $K$, Constien R, Donoghue M, Elbashir S, Geick A, Hadwiger P, Harborth J, John M, Kesavan V, Lavine G, Pandey RK, Racie T, Rajeev KG, Röhl I, Toudjarska I, Wang G, Wuschko S, Bumcrot D, Koteliansky V, Limmer S, Manoharan M, Vornlocher HP: Therapeutic silencing of an endogenous gene by systemic administration of modified siRNAs. Nature 2004, 432:173-8.

17. Wolfrum C, Shi S, Jayaprakash KN, Jayaraman M, Wang G, Pandey RK, Rajeev KG, Nakayama T, Charrise K, Ndungo EM, Zimmermann T, Koteliansky V, Manoharan M, Stoffel M: Mechanisms and optimization of in vivo delivery of lipophilic siRNAs. Nat Biotechnol 2007, 25:1149-57.

18. Dassie JP, Liu XY, Thomas GS, Whitaker RM, Thiel KW, Stockdale KR, Meyerholz DK, McCaffrey AP, McNamara JO, Giangrande PH: Systemic administration of optimized aptamer-siRNA chimeras promotes regression of PSMA-expressing tumors. Nat Biotechnol 2009, 27:839-49.

19. Morrissey DV, Lockridge JA, Shaw L, Blanchard K, Jensen K, Breen W, Hartsough K, Machemer L, Radka S, Jadhav V, Vaish N, Zinnen S, Vargeese C, Bowman K, Shaffer CS, Jeffs LB, Judge A, MacLachlan I, Polisky B: Potent and persistent in vivo anti-HBV activity of chemically modified siRNAs. Nat Biotechnol 2005, 23:1002-7.

20. Zimmermann TS, Lee AC, Akinc A, Bramlage B, Bumcrot D, Fedoruk MN, Harborth J, Heyes JA, Jeffs LB, John M, Judge AD, Lam K, McClintock K, Nechev LV, Palmer LR, Racie T, RöhI I, Seiffert S, Shanmugam S, Sood V, Soutschek J, Toudjarska I, Wheat AJ, Yaworski E, Zedalis W, Koteliansky V, Manoharan M, Vornlocher HP, MacLachlan I: RNAi-mediated gene silencing in non-human primates. Nature 2006, 441:111-4.

21. Abrams MT, Koser ML, Seitzer J, Williams SC, DiPietro MA, Wang W, Shaw AW, Mao X, Jadhav V, Davide JP, Burke PA, Sachs AB, Stirdivant SM, SeppLorenzino $L$ : Evaluation of efficacy, biodistribution, and inflammation for a potent siRNA nanoparticle: effect of dexamethasone cotreatment. Mol Ther 2010, 18:171-80.

22. Akinc A, Querbes W, De S, Qin J, Frank-Kamenetsky M, Jayaprakash KN, Jayaraman M, Rajeev KG, Cantley WL, Dorkin JR, Butler JS, Qin L, Racie T, Sprague A, Fava E, Zeigerer A, Hope MJ, Zerial M, Sah DW, Fitzgerald K, Tracy MA, Manoharan M, Koteliansky V, Fougerolles AD, Maier MA: Targeted Delivery of RNAi Therapeutics With Endogenous and Exogenous Ligand-Based Mechanisms. Mol Ther 2010, 18:1357-64.

23. Rozema DB, Lewis DL, Wakefield DH, Wong SC, Klein JJ, Roesch PL, Bertin SL, Reppen TW, Chu Q, Blokhin AV, Hagstrom JE, Wolff JA: Dynamic polyconjugates for targeted in vivo delivery of siRNA to hepatocytes. Proc Natl Acad Sci USA 2007, 104:12982-7.

24. Bartlett DW, Su H, Hildebrandt IJ, Weber WA, Davis ME: Impact of tumorspecific targeting on the biodistribution and efficacy of siRNA nanoparticles measured by multimodality in vivo imaging. Proc Natl Acad Sci USA 2007, 104:15549-54.

25. Semple SC, Akinc A, Chen J, Sandhu AP, Mui BL, Cho CK, Sah DW, Stebbing D, Crosley EJ, Yaworski E, Hafez IM, Dorkin JR, Qin J, Lam K, Rajeev KG, Wong KF, Jeffs LB, Nechev L, Eisenhardt ML, Jayaraman M, Kazem M, Maier MA, Srinivasulu M, Weinstein MJ, Chen Q, Alvarez R, Barros SA, De S, Klimuk SK, Borland T, Kosovrasti V, Cantley WL, Tam YK, Manoharan M, Ciufolini MA, Tracy MA, de Fougerolles A, Maclachlan I, Cullis PR, Madden TD, Hope MJ: Rational design of cationic lipids for siRNA delivery. Nat Biotechnol 2010, 28:172-6.

26. Frank-Kamenetsky M, Grefhorst A, Anderson NN, Racie TS, Bramlage B, Akinc A, Butler D, Charisse K, Dorkin R, Fan Y, Gamba-Vitalo C, Hadwiger P, Jayaraman M, John M, Jayaprakash KN, Maier M, Nechev L, Rajeev KG, Read T, Röhl I, Soutschek J, Tan P, Wong J, Wang G, Zimmermann T, de Fougerolles A, Vornlocher HP, Langer R, Anderson DG, Manoharan M, Koteliansky V, Horton JD, Fitzgerald K: Therapeutic RNAi targeting PCSK9 acutely lowers plasma cholesterol in rodents and LDL cholesterol in nonhuman primates. Proc Natl Acad Sci USA 2008, 105:11915-20.

27. Akinc A, Goldberg M, Qin J, Dorkin JR, Gamba-Vitalo C, Maier M, Jayaprakash KN, Jayaraman M, Rajeev KG, Manoharan M, Koteliansky V, Röhl I, Leshchiner ES, Langer R, Anderson DG: Development of lipidoidsiRNA formulations for systemic delivery to the liver. Mol Ther 2009, 17:872-9.

28. Love KT, Mahon KP, Levins CG, Whitehead KA, Querbes W, Dorkin JR, Qin J, Cantley W, Qin LL, Racie T, Frank-Kamenetsky M, Yip KN, Alvarez R, Sah DW, de Fougerolles A, Fitzgerald K, Koteliansky V, Akinc A, Langer R, Anderson DG: Lipid-like materials for low-dose, in vivo gene silencing. Proc Natl Acad Sci USA 2010, 107:1864-9.

29. Judge AD, Robbins M, Tavakoli I, Levi J, Hu L, Fronda A, Ambegia E, McClintockK, MacLachlan I: Confirming the RNAi-mediated mechanism of action of siRNA-based cancer therapeutics in mice. J Clin Invest 2009, 119:661-73.

30. Song E, Zhu P, Lee SK, Chowdhury D, Kussman S, Dykxhoorn DM, Feng Y, Palliser D, Weiner DB, Shankar P, Marasco WA, Lieberman J: Antibody mediated in vivo delivery of small interfering RNAs via cell-surface receptors. Nat Biotechnol 2005, 23:709-17.

31. Peer D, Zhu P, Carman CV, Lieberman J, Shimaoka M: Selective gene silencing in activated leukocytes by targeting siRNAs to the integrin lymphocyte function-associated antigen-1. Proc Natl Acad Sci USA 2007, 104:4095-100

32. Peer D, Park EJ, Morishita Y, Carman CV, Shimaoka M: Systemic leukocytedirected siRNA delivery revealing cyclin D1 as an anti-inflammatory target. Science 2008, 319:627-30.

33. Aouadi M, Tesz GJ, Nicoloro SM, Wang M, Chouinard M, Soto E, Ostroff GR, Czech MP: Orally delivered siRNA targeting macrophage Map4k4 suppresses systemic inflammation. Nature 2009, 458:1180-4.

34. Jackson AL, Linsley PS: Recognizing and avoiding siRNA off-target effects for target identification and therapeutic application. Nat Rev Drug Discov 2010, 9:57-67.

35. Jackson AL, Bartz SR, Schelter J, Kobayashi SV, Burchard J, Mao M, Li B, Cavet G, Linsley PS: Expression profiling reveals off-target gene regulation by RNAi. Nat Biotechnol 2003, 21:635-7.

36. Jackson AL, Burchard J, Schelter J, Chau BN, Cleary M, Lim L, Linsley PS: Widespread siRNA "off-target" transcript silencing mediated by seed region sequence complementarity. RNA 2006, 12:1179-87.

37. Birmingham A, Anderson EM, Reynolds A, Ilsley-Tyree D, Leake D, Fedorov Y, Baskerville S, Maksimova E, Robinson K, Karpilow J, Marshall WS, 
Khvorova A: 3' UTR seed matches, but not overall identity, are associated with RNAi off-targets. Nat Methods 2006, 3:199-204.

38. Grimm D, Streetz KL, Jopling CL, Storm TA, Pandey K, Davis CR, Marion P, Salazar F, Kay MA: Fatality in mice due to oversaturation of cellular microRNA/short hairpin RNA pathways. Nature 2006, 441:537-41.

39. Khan AA, Betel D, Miller ML, Sander C, Leslie CS, Marks DS: Transfection of small RNAs globally perturbs gene regulation by endogenous microRNAs. Nat Biotechnol 2009, 27:549-55.

40. Hornung V, Guenthner-Biller M, Bourquin C, Ablasser A, Schlee M, Uematsu S, Noronha A, Manoharan M, Akira S, de Fougerolles A, Endres S, Hartmann G: Sequence-specific potent induction of IFN-alpha by short interfering RNA in plasmacytoid dendritic cells through TLR7. Nat Med 2005, 11:263-70.

41. Judge AD, Sood V, Shaw JR, Fang D, McClintock K, MacLachlan I: Sequence-dependent stimulation of the mammalian innate immune response by synthetic siRNA. Nat Biotechnol 2005, 23:457-62.

42. Sioud M: Induction of inflammatory cytokines and interferon responses by double-stranded and single-stranded siRNAs is sequence-dependent and requires endosomal localization. $\mathrm{J} \mathrm{Mol} \mathrm{Biol}$ 2005, 348:1079-90.

43. Alemán LM, Doench J, Sharp PA: Comparison of siRNA-induced offtarget RNA and protein effects. RNA 2007, 13:385-95.

44. Bilanges B, Stokoe D: Direct comparison of the specificity of gene silencing using antisense oligonucleotides and RNAi. Biochem J 2005, 388:573-83.

45. Fisher AA, Ye D, Sergueev DS, Fisher MH, Shaw BR, Juliano RL: Evaluating the specificity of antisense oligonucleotide conjugates. A DNA array analysis. J Biol Chem 2002, 277:22980-4.

46. Irwin RD, Parker JS, Lobenhofer EK, Burka LT, Blackshear PE, Vallant MK, Lebetkin EH, Gerken DF, Boorman GA: Transcriptional profiling of the left

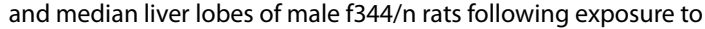
acetaminophen. Toxicol Pathol 2005, 33:111-7.

47. Lin Z, Crockett DK, Jenson SD, Lim MS, Elenitoba-Johnson KS: Quantitative proteomic and transcriptional analysis of the response to the 338 mitogen-activated protein kinase inhibitor SB2035380 in transformed follicular lymphoma cells. Mol Cell Proteomics 2004:820-33.

48. Robbins M, Judge A, MacLachlan I: siRNA and innate immunity. Oligonucleotides 2009, 19:89-102.

49. Yoneyama M, Kikuchi M, Natsukawa T, Shinobu N, Imaizumi T, Miyagishi M, Taira K, Akira S, Fujita T: The RNA helicase RIG-I has an essential function in double-stranded RNA-induced innate antiviral responses. Nat Immunol 2004, 5:730-7.

50. Meurs E, Chong K, Galabru J, Thomas NS, Kerr IM, Williams BR, Hovanessian AG: Molecular cloning and characterization of the human double-stranded RNA-activated protein kinase induced by interferon. Cell 1990, 62:379-90

51. Robbins M, Judge A, Ambegia E, Choi C, Yaworski E, Palmer L, McClintock K, MacLachlan I: Misinterpreting the therapeutic effects of small interfering RNA caused by immune stimulation. Hum Gene Ther 2008 , 19:991-9.

52. Judge AD, Robbins M, Tavakoli I, Levi J, Hu L, Fronda A, Ambegia E, McClintock K, MacLachlan I: Confirming the RNAi-mediated mechanism of action of siRNA-based cancer therapeutics in mice. J Clin Invest 2009, 119:661-73.

53. Stewart VA, McGrath S, Krieg AM, Larson NS, Angov E, Smith CL, Brewer TG, Heppner DG Jr: Activation of innate immunity in healthy Macaca mulatta macaques by a single subcutaneous dose of GMP CPG 7909: safety data and interferon-inducible protein-10 kinetics for humans and macaques. Clin Vaccine Immunol 2008, 15:221-6.

54. Vicari AP, Schmalbach T, Lekstrom-Himes J, Morris ML, Al-Adhami MJ, Laframboise C, Leese P, Krieg AM, Efler SM, Davis HL: Safety, pharmacokinetics and immune effects in normal volunteers of CPG 10101 (ACTILON), an investigational synthetic toll-like receptor 9 agonist. Antivir Ther 2007, 12:741-51.

55. Goodchild A, Nopper N, King A, Doan T, Tanudji M, Arndt GM, Poidinger $M$, Rivory LP, Passioura T: Sequence determinants of innate immune activation by short interfering RNAs. BMC Immuno/ 2009, 10:40.

56. Monteith DK, Levin AA: Synthetic oligonucleotides: the development of antisense therapeutics. Toxicol Pathol 1999, 27:8-13.

57. Chen C, Ridzon DA, Broomer AJ, Zhou Z, Lee DH, Nguyen JT, Barbisin M, Xu NL, Mahuvakar VR, Andersen MR, Lao KQ, Livak KJ, Guegler KJ: Real- time quantification of microRNAs by stem-loop RT-PCR. Nucleic Acids Res 2005, 33:e179.

58. Rayburn ER, Zhang R: Antisense, RNAi, and gene silencing strategies for therapy: mission possible or impossible? Drug Discov Today 2008, 13:513-21.

59. DeVincenzo J, Cehelsky JE, Alvarez R, Elbashir S, Harborth J, Toudjarska I, Nechev L, Murugaiah V, Van Vliet A, Vaishnaw AK, Meyers R: Evaluation of the safety, tolerability and pharmacokinetics of ALN-RSV01, a novel RNAi antiviral therapeutic directed against respiratory syncytial virus (RSV). Antiviral Res 2008, 77:225-31.

60. Alnylam Pharmaceuticals Inc: [http://alnylam.com/Programs-andPipeline/index.php]

61. Registry of Federally and Privately Supported Clinical Trials. Phase II open label multicenter study for age related macular degeneration comparing an investigational drug PF-04523655 versus Lucentis in the treatment of subjects with choroidal neovascularization (MONET Study) [http://clinicaltrials.gov/ct2/show/NCT00713518?term=PF04523655\&rank=1]

62. Registry of Federally and Privately Supported Clinical Trials. Prospective randomized multi-center comparator study evaluating efficacy and safety of PF-04523655 versus laser in subjects with diabetic macular edema (DEGAS) [http://clinicaltrials.gov/ct2/show/ NCT00701181?term=PF04523655\&rank=2]

63. Registry of Federally and Privately Supported Clinical Trials. I5NP for Prophylaxis of Delayed Graft Function in Kidney Transplantation [http://clinicaltrials.gov/ct2/show/NCT00802347?term=QPI1002\&rank=1]

64. Registry of Federally and Privately Supported Clinical Trials. A dose escalation and safety study of I5NP to prevent acute kidney injury (AKI) in patients at high risk of AKI undergoing major cardiovascular surgery (QRK.004) [http://clinicaltrials.gov/ct2/show/NCT00683553?term=QPI1002\&rank=2]

65. Quark Pharma. QPI-1002 for AKI [http://www.quarkpharma.com/qbien/products/QPI-1002/

66. Registry of Federally and Privately Supported Clinical Trials. Dose escalation trial to evaluate the safety tolerability pharmacokinetics and pharmacodynamics of intravenous ALN-VSP02 In patients with advanced solid tumors with liver involvement [http://clinicaltrials.gov/ ct2/show/NCT00882180?term=aln-vsp\&rank=1]

67. Registry of Federally and Privately Supported Clinical Trials. Safety Study of CALAA-01 to Treat Solid Tumor Cancers [http:// clinicaltrials.gov/ct2/show/NCT00689065?term=calaa-01\&rank=1

68. Registry of Federally and Privately Supported Clinical Trials. Study With Atu027 in patients with advanced solid cancer [http://clinicaltrials.gov/ ct2/show/NCT00938574?term=atu 027\&recr=Open\&rank=1]

69. Aleku M, Schulz P, Keil O, Santel A, Schaeper U, Dieckhoff B, Janke O, Endruschat J, Durieux B, Röder N, Löffler K, Lange C, Fechtner M, Möpert K, Fisch G, Dames S, Arnold W, Jochims K, Giese K, Wiedenmann B, Scholz A, Kaufmann J: Atu027, a liposomal small interfering RNA formulation targeting protein kinase N3, inhibits cancer progression. Cancer Res 2008, 68:9788-98.

70. Zabecor Pharmaceuticals. ZaBeCor Pharmaceuticals begins phase ii clinical trial in asthma patients following positive phase i results [http://www.zabecor.com/news/news092209.php]

71. Tekmira Pharmaceuticals Corp Website [http:// www.tekmirapharm.com/Programs/Products.asp

72. BioSpace Acuity Pharmaceuticals reports positive phase II Results for bevasiranib in wet AMD [http://www.biospace.com/ news story.aspx? NewsEntityld $=29474$

73. Registry of Federally and Privately Supported Clinical Trials [http:// www.clinicaltrial.gov/ct2/show/NCT00557791]. Safety and efficacy study evaluating the combination of bevasiranib and Lucentis therapy in wet AMD (CARBON)

74. Opko Health [http://www.opko.com/research/?doc=ophthalmics]

75. Genomeweb Allergan drops development of siRNA Rx for AMD on poor phase II data [http://www.genomeweb.com/rnai/allergan-dropsdevelopment-sirna-rx-amd-poor-phase-ii-data]

76. Medical News Today. Sirna Therapeutics reports final results from phase 1 study on its RNAi-based therapeutic for age-related macular degeneration [http://www.medicalnewstoday.com/articles/49334.php]

77. Koldehoff M, Steckel NK, Beelen DW, Elmaagacli AH: Therapeutic application of small interfering RNA directed against bcr-abl 
transcripts to a patient with imatinib-resistant chronic myeloid leukaemia. Clin Exp Med 2007, 7:47-55.

78. Leachman SA, Hickerson RP, Schwartz ME, Bullough EE, Hutcherson SL, Boucher KM, Hansen CD, Eliason MJ, Srivatsa GS, Kornbrust DJ, Smith FJ, McLean WI, Milstone LM, Kaspar RL: First-in-human mutation-targeted siRNA phase lb trial of an inherited skin disorder. Mol Ther 2010, 18:442-6.

doi: 10.1186/1758-907X-1-14

Cite this article as: Vaishnaw et al., A status report on RNAi therapeutics Silence 2010, 1:14

Submit your next manuscript to BioMed Central and take full advantage of:

- Convenient online submission

- Thorough peer review

- No space constraints or color figure charges

- Immediate publication on acceptance

- Inclusion in PubMed, CAS, Scopus and Google Scholar

- Research which is freely available for redistribution

Submit your manuscript at www.biomedcentral.com/submit
() BioMed Central 